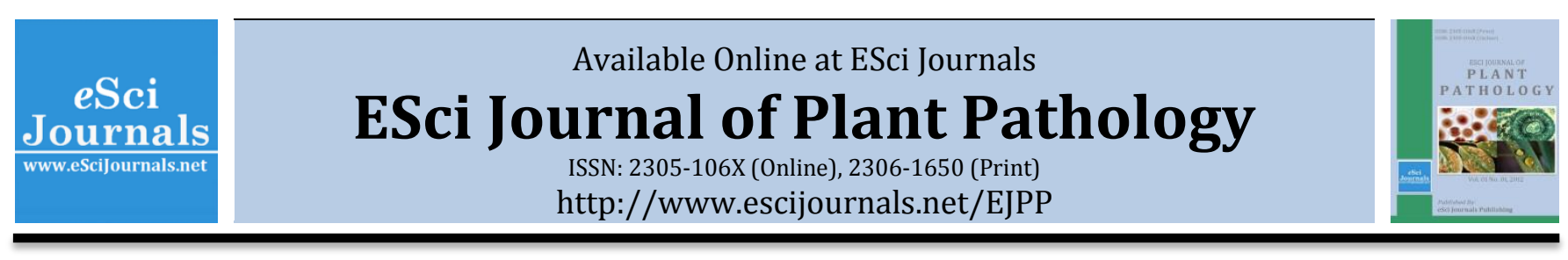

\title{
TOXIGENICITY OF FUSARIUM SPECIES IN GIBBERELLA FUJIKUROI SPECIES COMPLEX (GFSC) ASSOCIATED WITH STALK AND EAR ROT DISEASE OF CORN
}

\author{
aTiti Darnetty*, bBaharuddin Salleh \\ a Department of Plant Pests and Diseases, Faculty of Agriculture, Andalas University, Limau Manis, Padang, Indonesia. \\ b School of Biological Sciences, Universiti Sains Malaysia, 11800 Minden, Pulau Pinang, Malaysia.
}

\begin{abstract}
A B S T R A C T
Fusarium stalk and ear rot disease did not only cause significant losses of yield but also produced mycotoxins that are harmful to animals and human. This study was conducted to elucidate three major mycotoxins i.e. fumonisin B1 (FUMB $\left.{ }_{1}\right)$, moniliformin (MON), and beauvericin (BEA) produced by the Fusarium spp. isolated from corn showing typical stalk and ear rot symptoms in Indonesia, Malaysia and Thailand. Twenty selected strains of Fusarium species in Gibberella fujikuroi species complex i.e. F.verticillioides, F. proliferatum, F. subglutinans, and F. konzum were analyzed for production of the three mycotoxins by using an Ultra Performance Liquid Chromatography (UPLC). All strains of $F$. verticillioides and $F$. proliferatum produced $\mathrm{FUMB}_{1}$ at high levelsand $\mathrm{MON}$ at low levels. Many strains of $F$. verticillioides $(67 \%)$ and F. proliferatum (50\%) did not produce BEA while the others produced BEA at low levels. Two strains of $F$. subglutinans did not produce $\mathrm{FUMB}_{1}$ but produced MON at low levels. One strain of $F$. subglutinans produced BEA and the other one did not produce the toxin. Two strains of $F$. konzum produced both MON and BEA at low levels but only one strain produced FUMB 1 at a low level. These mycotoxins have not been reported from Fusarium spp. in Gibberella fujikuroi species complex isolated form stalk and ear rot diseases of corn in these areas. Therefore, concerted efforts must be made to educate all stake holders about the presence and health hazards of these mycotoxins.
\end{abstract}

Keywords: Moniliformin (MON), fumonisin $\left(\mathrm{FUMB}_{1}\right)$, beauvericin (BEA).

\section{INTRODUCTION}

Many species of Fusarium in Gibberella fujikuroi species complex (Gfsc) such as $F$. verticillioides, F. proliferatum, and $F$. subglutinans have been known as the causal agents of stalk and ear rot diseases on corn in all major corn producers of the world (Referance). In addition, these Fusarium species are capable of producing a variety of mycotoxins, such as fumonisins (FUM), moniliformin (MON), and beauvericin (BEA) (Bottalico et al., 1989; Logrieco et al., 1995; Moretti et al., 1997; Chulze et al., 1998; Shephard et al., 1999). The occurrence of mycotoxins in this cereal grain is of great concern worldwide, because their presence in feeds and food is often associated with chronic or acute mycotoxicoses in livestock and, to a lesser extent, also in human (Charmley et al., 1995).

FUM are natural contaminants of cereal grains

* Corresponding Author:

Email: Darnetty_06@yahoo.com

(C) 2013 ESci Journals Publishing. All rights reserved. worldwide and are mostly found in corn and products derived from corn (Bullerman, 1996; Visconti, 1996; Weidenbörner et al., 2001), and is produced by a variety of Fusarium species mainly those in Gibberella fujikuroi species complex such as $F$. verticillioides, F. proliferatum, and some other related species e.g. F. fujikuroi, $F$. konzum, and $F$. nygamai (formally $F$. moniliforme; teleomorph Gibberella fujikuroi species complex) (Gelderblom et al., 1988; Thiel et al., 1991; Nelson et al., 1992). F. verticillioides is a pathogen of agriculturally important cereals, especially corn, and it is considered as one of the most important toxigenic fungi worldwide; as the main source of FUM contamination of food and feed products (Nelson et al., 1993; Moss, 1996). The most abundant FUM produced in nature is FUM $\mathrm{B}_{1}\left(\mathrm{FUMB}_{1}\right)$ that caused several chronic and acute diseases in human and animals (Gelderblom et al., 1988; Desjardins, 2006). According to Desjardins (2006), high levels of FUMB 1 have been found consistently in corn infected by strains of $F$. verticillioides and $F$. proliferatum, but $\mathrm{FUMB}_{1}$ 
production was discontinuous among the other species of the Gfsc. As stated by Nelson et al. (1991), strains of $F$. verticillioides generally produce moderate to high levels of fumonisins ( $400-4000 \mathrm{mg} / \mathrm{kg}$ ). Results of a study conducted by Acuna et al. (2005) showed that almost all strains of $F$. verticillioides $(97.1 \%)$ and $F$. proliferatum (97.1\%) produced $\mathrm{FUMB}_{1}(5.6-25846.4 \mathrm{mg} / \mathrm{kg})$ and $(6.9-3885.0 \mathrm{mg} / \mathrm{kg}$ ) respectively, while $F$. subglutinans did not produce FUM.

Like FUM, MON also was found widely in food and feeds infected by strains of Fusarium species in Gibberella fujikuroi species complex such as $F$. proliferatum, $F$. subglutinans, F. avenaceum, and F. tricinctum (Gutleb et al., 2002; Logrieco et al., 2002). Results of a survey conducted by Desjardins (2006) showed that in the Gfsc, MON production was widespread but not universal. Most notably, many strains of $F$. proliferatum, $F$. subglutinans, and $F$. thapsinum produced high levels of MON, but $F$. verticillioides very rarely produced MON. Individual species do vary widely in the frequency of MON-producing strains and in the levels of MON produced. Also stated by Leslie et al. (1995) that $F$. verticillioides produce little or no MON.

Beauvericin (BEA) is a mycotoxin produced by several Fusarium species, mainly by $F$. proliferatum, $F$. semitectum, and F. subglutinans (Moretti et al., 1997; Logrieco et al., 1998; Shephard et al., 1999). Although most of FUM-producing Fusarium species also produced BEA, however, the frequency and levels of BEA differ between individual strains (Desjardins, 2006). $F$. verticillioides and $F$. proliferatum are important corn pathogens causing stalk and ear rot all over the world including Southeast Asia, can produce a variety of mycotoxins including BEA both in pre-harvested and in stored products (Bottalico et al., 1989; Logrieco et al., 1995; Moretti et al., 1997; Chulze et al., 1998; Shephard et al., 1999). According to Leslie et al. (2004), F. konzum produce variable but generally low to moderate amounts of BEA ( $4-320 \mu \mathrm{g} / \mathrm{g}$ ). Besides the threats, mycotoxin profiles also are important chemotaxonomic criteria in the identification and characterization of Fusarium species. Nelson et al. (1993), and Thrane and Hansen (1995) have revealed species-specific metabolite profiles of Fusarium species. Also, Fotso et al. (2002) found that individual species of Fusarium produced different classes and levels of secondary metabolites. For example, gibberellic acid (GA) could be used to differentiate $F$. fujikuroi with several other closely related species in Gibberella fujikuroi species complex (Nur Ain Izzati, 2007). So far, most studies of Fusarium mycotoxin profiles were using strains from the temperate region which might be different than those produced by tropical strains.

This study was conducted to elucidate toxigenecity of three most important mycotoxins i.e. $\mathrm{FUMB}_{1}, \mathrm{MON}$, and BEA produced by Fusarium species in Gibberella fujikuroi species complex isolated from corn showing typical stalk and ear rot symptoms in Indonesia, Malaysia, and Thailand.

\section{MATERIALS AND METHODS}

Strains and Chemicals: A total of 20 strains representing four Fusarium species i.e. F. verticillioides (12 strains), F. proliferatum (4 strains), F. subglutinans (2 strains), and F. konzum ( 2 strains) isolated from stalk and ear rot-infected corn plants were used to study the mycotoxin toxigenicity (Table 1 ). $\mathrm{FUMB}_{1}, \mathrm{MON}$, and BEA standards, sodium borate $\left(\mathrm{Na}_{2} \mathrm{~B}_{4} \mathrm{O}_{7}\right), 2$-mercaptoethanol, 2-ME $\left(\mathrm{HOCH}_{2} \mathrm{CH}_{2} \mathrm{SH}\right)$, tetrabutylammonium hydrogen sulphate (TBAHS). $\left(\mathrm{C}_{16} \mathrm{H}_{35} \mathrm{~N} \cdot \mathrm{H}_{2} \mathrm{SO}_{4}\right)$, and orthophthaldialdehyde, OPA were purchased from SigmaAldrich, USA. Sodium dihydrogen phosphate monohydrate $\left(\mathrm{NaH}_{2} \mathrm{PO}_{4}\right)$, potassium dihydrogen phosphate $\left(\mathrm{KH}_{2} \mathrm{PO}_{4}\right)$, potassium chloride $(\mathrm{KCl})$ from Univar, Australia. Orthophosphoric acid $\left(\mathrm{H}_{3} \mathrm{PO}_{4}\right)$, acetonitrile, ACN $\left(\mathrm{CH}_{3} \mathrm{CN}\right)$ HPLC grade, methanol, $\mathrm{MeOH}$ $\left(\mathrm{CH}_{3} \mathrm{OH}\right)$ HPLC grade, n-heptane $\left(\mathrm{C}_{7} \mathrm{H}_{16}\right)$ HPLC grade and dichloromethane $\left(\mathrm{CH}_{2} \mathrm{Cl}_{2}\right)$ were purchased from Fisher Scientific, UK and C18-SPE column from Supelco, USA.

Fusarium Culture Preparation: About $15 \mathrm{~g}$ of washed and dried corn grits were placed into $100 \mathrm{ml}$ Erlenmeyer flask, plugged with cotton wool and covered with aluminum foil, and autoclaved for $45 \mathrm{~min}$ at $15 \mathrm{psi}$, $121^{\circ} \mathrm{C}$. The sterile corn grits in Erlenmeyer flasks were inoculated with $1 \mathrm{ml}$ conidial suspension $\left(1 \times 10^{7}\right.$ conidia/ml). and then added with $5 \mathrm{ml}$ of sterile distilled water to keep the moisture of corn grits. The Erlenmeyer flask was daily hand-shaken to homogenize the conidial suspension and incubated for 30 days in the dark.

Mycotoxin Extraction, Clean up, and Chemical analysis: All cultured media were extracted, cleaned up, and assayed for the following mycotoxins by using an Ultra Performance Liquid Chromatography (UPLC) as follows.

Fumonisin $\mathbf{B}_{\mathbf{1}}$ (FUMB $\mathbf{F}_{\mathbf{1}}$ ): The method employed for fumonisin extraction was adapted from Nelson et al. (1991). 
ESci J. Plant Pathol. 02 (03) 2013. 147-154

Table 1. Strains of Fusarium species in Section Liseola isolated from corn showing typical stalk and ear rot symptoms in Indonesia, Malaysia and Thailand used for mycotoxin toxigenicity analysis.

\begin{tabular}{llllll}
\hline $\begin{array}{l}\text { Strains } \\
\text { code }\end{array}$ & Location & Region & Country & $\begin{array}{l}\text { Organ } \\
\text { Ear, Stalk }\end{array}$ & Species name \\
\hline R1060 & Bukit Tamiang & Perlis & Malaysia & Ear & F. verticilioides \\
P4450 & MARDI Bertam & Penang & Malaysia & Ear & F. verticilioides \\
K24040 & Gurun & Kedah & Malaysia & Stalk & F. verticilioides \\
K24050 & Gurun & Kedah & Malaysia & Stalk & F. verticilioides \\
OLN01880 & Bogor & West Java & Indonesia & Ear & F. verticilioides \\
OLN02000 & TulungAgung & East Java & Indonesia & Ear & F. verticilioides \\
OLN02270 & Medan & North Sumatra & Indonesia & Ear & F. verticilioides \\
OLN02600 & Medan & North Sumatra & Indonesia & Stalk & F. verticilioides \\
OLN02660 & Agam & West Sumatra & Indonesia & Ear & F. verticilioides \\
OLN03440 & Padang-Pariaman & West Sumatra & Indonesia & Stalk & F. verticilioides \\
HLN01550 & Tak Fa & Nankhon Sawan & Thailand & Stalk & F. verticilioides \\
HLN01800 & Songkhla & Hat Yai & Thailand & Stalk & F. verticilioides \\
Q55650 & Sri Aman & Sarawak & Malaysia & Ear & F. proliferatum \\
OLN01870 & Bogor & West Java & Indonesia & Ear & F. proliferatum \\
OLN03810 & Banda Aceh & Aceh & Indonesia & Ear & F. proliferatum \\
HLN01600 & Tak & Tak & Thailand & Stalk & F. proliferatum \\
S48950 & Ranau & Sabah & Malaysia & Stalk & F. subglutinans \\
OLN01860 & Bogor & West Sumatra & Indonesia & Ear & F. subglutinans \\
OLN03430 & Padang-Pariaman & West Sumatra & Indonesia & Stalk & F. konzum \\
OLN04920 & Agam & West Sumatra & Indonesia & Stalk & F. konzum \\
\hline
\end{tabular}

About $10 \mathrm{~g}$ of inoculated corn grits were suspended with $50 \mathrm{ml}$ of acetonitrile: water $(50: 50, \mathrm{v} / \mathrm{v})$, and homogenized in a Waring blender for 5 minutes. The mixture was filtered through a Whatman no. 4 filter paper and separated by using a separatory funnel; the bottom layer was taken and evaporated to near dryness at $65^{\circ} \mathrm{C}$ by using a rotary evaporator (Buchi 461, Switzerland). The solvent residue was dissolved in $1 \mathrm{ml}$ of methanol.

The filtrate was cleaned up on a C-18 solid phase extraction (SPE) column. The filtrate $(1 \mathrm{ml})$ was added to $2.5 \mathrm{~mL}$ of $1 \%$ aqueous $\mathrm{KCl}$ and was passed through the C18-SPE column, which had been preconditioned with methanol ( $5 \mathrm{ml}$ ), followed by $5 \mathrm{ml}$ of $1 \%$ aqueous $\mathrm{KCl}$. The column was then washed with $3 \mathrm{ml}$ of $1 \%$ aqueous $\mathrm{KCL}$, followed by $2 \mathrm{ml}$ of acetonitrile: $1 \%$ aqueous $\mathrm{KCl}(10: 90, \mathrm{v} / \mathrm{v})$. The fumonisins were eluted off the $\mathrm{C}_{18}$-SPE column with $2 \mathrm{ml}$ of acetonitrile: water (50:50, v/v) and was ready for the pre-column derivatization.

O-Phthaldialdehyde (OPA) derivatising agent was prepared by adding methanol (1ml) to OPA (40 mg) and diluted with $5 \mathrm{~mL} 0.1 \mathrm{~mol} \mathrm{~L}^{-1}$ sodium borate, then
$50 \mu \mathrm{l}$ of 2-ME was added to the mixture. This reagent is stable in the dark for up to 8 days in capped, aluminum foil-covered vials (Abramovic et al. 2005). The OPA reagent $(200 \mu \mathrm{l})$ was added to a sample or standard solution $(50 \mu \mathrm{l})$ and was mixed well. Five $\mu \mathrm{L}$ of this solution was injected into the UPLC unit, within four minutes after the derivatization. The mobile phase was methanol: mixture $(0.1 \%$ sodium dehydrogen phosphate with pH 3.35 adjusted with o-phosphoric acid) (78:22). Detection of fumonisin was by fluorescence (FLR) detector with wavelength set at $305 \mathrm{~nm}$ for excitation and $432 \mathrm{~nm}$ for emission. Calculation of $\mathrm{FUMB}_{1}$ concentrations of tested samples was based on peak areas of samples compared with those of standards.

Moniliformin (MON): MON extraction was carried out by following the techniques described by Burmeister et al. (1979). About $10 \mathrm{~g}$ of inoculated corn grits were soaked with $100 \mathrm{ml}$ of $1 \%$ tetrabutylammonium hydrogen sulphate (TBAHS) in $\mathrm{dd}_{2} \mathrm{O}$ and shaken for 30 minutes. Then the shaken corn grits were filtered through a Whatman no.4 filter paper and defatted with $10 \mathrm{ml}$ of $\mathrm{n}$-hexane in a separating funnel and the bottom layer was taken. Dichloromethane (same volume as 
sample) was added to the sample solution and mixed gently. The mixture was separated by using a separatory funnel and the sample solution at bottom layer was taken and evaporated in a Buchi (Switzerland) rotary vacuum evaporator at $55^{\circ} \mathrm{C}$. Then, the soluble residue was dissolved in $1 \mathrm{ml}$ dichloromethane, filtered through 0.2 um Millipore filter, and kept in a bottle at $5^{\circ} \mathrm{C}$ until used. The filtrate was cleaned up by the $\mathrm{C}_{18}$-SPE column as described for $\mathrm{FUMB}_{1}$. Mobile phase was acetonitrile and mixture $(50 \mathrm{ml}$ of $40 \%$ tetrabutylammonium hydrogen sulphate, $100 \mathrm{ml}$ of $1.1 \mathrm{M}$ potassium

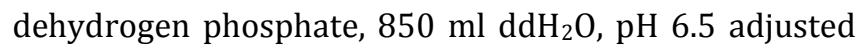
by $5 \mathrm{~N} \mathrm{KOH})$ (8:92). MON was detected by a photodiode array (PDA) detector at wavelength $229 \mathrm{~nm}$.

Beauvericin (BEA): Procedure for beauvericin detection was adapted from Logrieco et al. (1998). About $15 \mathrm{~g}$ of corn grits were soaked overnight with 75 $\mathrm{ml}$ of acetonitrile: methanol: water $(16: 3: 1 ; \mathrm{v} / \mathrm{v})$, and milled in a Waring blender for five minutes. The milled corn grits were filtered through a Whatman no. 4 filter paper, and then defatted twice with $25 \mathrm{ml}$ of $\mathrm{n}$-hexane in a separating funnel. The bottom layer was evaporated to near dryness at $80^{\circ} \mathrm{C}$ by using a vacuum rotary evaporator (Buchi 461, Switzerland). The solvent residue was dissolved in $50 \mathrm{ml}$ of methanol: water (1:1 $\mathrm{v} / \mathrm{v}$ ) and extracted twice with $25 \mathrm{ml}$ of dichloromethane. Then, the solution was evaporated and redissolved in 1 $\mathrm{ml}$ of methanol, filtered through 0.2 um Millipore filter, and kept in $5 \mathrm{ml}$ Bijoux bottle at $5^{\circ} \mathrm{C}$ condition until used. The filtrate was cleaned up by the $\mathrm{C}_{18}$-SPE column as described for $\mathrm{FUMB}_{1}$. Mobile phase used for BEA detection was methanol: water $(85: 15 ; \mathrm{v} / \mathrm{v})$ with flow rate a $0.5 \mathrm{ml} / \mathrm{min}$. BEA was detected by a photodiode array (PDA) detector at wavelength $205 \mathrm{~nm}$.

\section{RESULTS AND DISCUSSION}

The results of this study showed that each strain of Fusarium species has a different ability to produce the three mycotoxins, $\mathrm{FUMB}_{1}, \mathrm{MON}$, and BEA. Representative production of $\mathrm{FUMB}_{1}, \mathrm{MON}$, and BEA by each strain were indicated in Figure 1. Concentrations of three mycotoxins produced by Fusarium species were shown in Table 2. FUMB $_{1}$ were produced in high concentrations up to $32756.3 \mu \mathrm{g} / \mathrm{g}$ mainly by strains of $F$. verticillioides and $F$. proliferatum, although there were some strains that produced $\mathrm{FUMB}_{1}$ with rather low concentrations. In general, the productions of $\mathrm{FUMB}_{1}$ by $F$. verticillioides were higher than those by $F$. proliferatum. These two fungi were known as the major
FUM-producing species (Gelderblom et al., 1988; Thiel et al., 1991; Nelson et al., 1992). Also, the two species of Fusarium always produce FUM in high levels, while others in Gfsc do not always produce FUM as stated by Desjardins (2006). On the contrary, two strains of $F$. subglutinans tested did not produce the $\mathrm{FUMB}_{1}$. As mentioned by Nelson et al. (1992) and Leslie et al. (2004) that F. subglutinans produced little or no FUMB 1 . The results of this study were similar with those by Acuna et al. (2005) in which almost all strains of $F$. verticillioides and $F$. proliferatum produced $\mathrm{FUMB}_{1}$ at the levels ranging from 5.6 to $25846.4 \mathrm{mg} / \mathrm{kg}$ and from 6.9 to $3885.0 \mathrm{mg} / \mathrm{kg}$ respectively, while $F$. subglutinans did not produce $\mathrm{FUMB}_{1}$. In the presence study, one strain of F. konzum produce $\mathrm{FUMB}_{1}$ at low level, and the other strain did not produce the toxin. This is in accordance with that proposed by Leslie et al. (2004) that G. konza (teleomorph of $F$. konzum) strains produced little or no fumonisins (up to $120 \mu \mathrm{g} / \mathrm{g}$ by one strain).

Moniliformin (MON) derived from $F$. moniliforme, the fungal species that was identified as the original toxin producer in the United State in 1993 (Cole et al., 1973; Marasas et al., 1984). However, after re-investigation of MON producing strains indicated that some strains were misidentified as $F$. proliferatum and the others were $F$. nygamai (Marasas et al, 1988). Subsequent studies have confirmed that MON rarely produced by $F$. moniliforme and the amount of MON is not more than trace levels (now renamed as F. verticillioides) (Nelson et al. 1993; Leslie et al. 1996). Rabie et al. (1982) stated that the species now recognized as $F$. verticillioides does not generally produce significant levels of MON even though some strains may produce the mycotoxin when grown on corn. However, in this study all strains of $F$. verticillioides produced MON at low levels. The results of this study are not unexpected because $F$. verticillioides has been found to produce MON even though in a very small amount (Leslie et al., 1995) and interestingly, results of a research conducted by Moretti et al (2004) indicated that all strains from banana fruits identified morphologically as $F$. verticillioides and biologically as MP-A produced MON while none of the strains produced FUM and the $F$. verticillioides strains from corn produced FUMB $_{1}(20$ - $5645 \mu \mathrm{g} / \mathrm{g})$ but did not produce MON. Based on these results, it can be concluded that there are strains of $F$. verticillioides that can produce MON at relatively high levels. Therefore, the results of the study by Moretti et al. (2004) cancorroboratethe results of our 
findings. MON formation by strains of $F$. proliferatum and $F$. subglutinans in the present study was also in accordance with the results of several researchers such as Marasas et al. (1984), Abbas et al. (1989), Chelkowski et al. (1990), Leslie et al. (1996), and Desjardins et al. (1997). Two strains of $F$. konzum produced MON at low levels and there has been no previous report of MON production by F. konzum.

BEA production is widely distributed in Fusarium species including both FUM-producing and trichothecene-producing species (Bottalico et al, 1995; Shephard et al., 1999; Desjardins et al., 2000; Fotso et al., 2002; Logrieco et al., 2002, and Leslie et al., 2004). In the present study, eight strains of $F$. verticillioides did not produce BEA while the other four strains produced BEA at the low levels $(0.6-2.8 \mu \mathrm{g} / \mathrm{g})$. These results are in agreement with those reported by Desjardins (2006), that $F$. verticillioides produced little or no BEA. Two of the four tested strains of $F$. proliferatum and one of two tested strains of $F$. subglutinans produced BEA at low levels.

The productions of BEA by the strains of the two species are in accordance with the results of studies that have been published by many researchers such as Krska et al. (1996), Moretti et al. (1997), Logrieco et al. (1998), and Shephard et al. (1999). In this study the amounts of BEA produced by $F$. proliferatum and $F$. subglutinans were very low when compared with the results of the research that have been reported by all researchers mentioned above. According to Desjardins (2006) individual species do vary widely in frequency of BEAproducing strains and in the level of BEA produced.

Table 2. Toxigenicity of strains of Fusarium spp. in Gibberella fujikuroi species complex isolated from corn showing typical stalk and ear rot symptoms in Indonesia, Malaysia and Thailand.

\begin{tabular}{|c|c|c|c|c|}
\hline \multirow[t]{2}{*}{ Fusarium species } & \multirow[t]{2}{*}{ Strains } & \multicolumn{2}{|c|}{ Concentration $(\mu \mathrm{g} / \mathrm{g})$} & \multirow[b]{2}{*}{ BEA } \\
\hline & & FUM B $_{1}$ & MON & \\
\hline \multirow[t]{12}{*}{ F.verticillioides } & R1060 & 15996.7 & 1.4 & ND \\
\hline & P4450 & 25367.1 & 1.9 & 0.8 \\
\hline & K24040 & 20624.7 & 1.9 & ND \\
\hline & K24050 & 4550.4 & 1.7 & ND \\
\hline & OLN01880 & 12606.3 & 1.8 & ND \\
\hline & OLN02000 & 29471.4 & 2.6 & 2.8 \\
\hline & OLN02270 & 16329.6 & 2.5 & 2.7 \\
\hline & OLN02600 & 32756.3 & 0.7 & ND \\
\hline & OLN02660 & 9926.8 & 3.2 & ND \\
\hline & OLN03440 & 715.6 & 4.9 & ND \\
\hline & HLN01550 & 843.5 & 1.4 & ND \\
\hline & HLN01800 & 27692.9 & 1.9 & 0.6 \\
\hline \multirow[t]{4}{*}{ F. proliferatum } & Q55650 & 156.2 & 1.7 & ND \\
\hline & OLN01870 & 13217.6 & 2.3 & 3.2 \\
\hline & OLN03810 & 8933.1 & 1.2 & ND \\
\hline & HLN01610 & 21423.1 & 3.0 & 0.1 \\
\hline \multirow[t]{2}{*}{ F. subglutinans } & S48950 & ND & 1.6 & 3.9 \\
\hline & OLN01860 & ND & 1.1 & ND \\
\hline \multirow[t]{2}{*}{ F. konzum } & OLN03430 & 30.1 & 2.1 & 1.2 \\
\hline & OLN04920 & ND & 0.9 & 1.0 \\
\hline
\end{tabular}

FUMB $_{1}=$ Fumonisin $B_{1} ;$ MON= Moniliformin; BEA= Beauvericin; ND= Not Detected.

In conclusion, all strains of $F$. verticillioides and $F$. proliferatum produced $\mathrm{FUMB}_{1}$ at high levels ranging from 715.6 to $32756.3 \mu \mathrm{g} / \mathrm{g}$ and 156.2 to $21423.1 \mu \mathrm{g} / \mathrm{g}$, respectively while produced MON at low levels from 0.7 to $4.9 \mu \mathrm{g} / \mathrm{g}$ and 1.2 to $3.0 \mu \mathrm{g} / \mathrm{g}$, respectively. In general, production of $\mathrm{FUMB}_{1}$ by strains of $F$. proliferatum was relatively low compared to $F$. verticillioides. Many strains of $F$. verticillioides (67\%) and F. proliferatum (50\%) did not produce BEA while the others produced BEA at low levels, up to 2.8 and $3.2 \mu \mathrm{g} / \mathrm{g}$, respectively. Two strains of $F$. subglutinans tested did not produce $\mathrm{FUMB}_{1}$ but produced MON at low levels, 1.1 and $1.6 \mu \mathrm{g} / \mathrm{g}$.

One strain of $F$. subglutinans produced BEA $(3.9 \mu \mathrm{g} / \mathrm{g})$ and the other one did not produce the toxin. Two strains of $F$. konzum produced both MON and BEA at low levels but only one strain produced $\mathrm{FUMB}_{1}$ at a low level. 

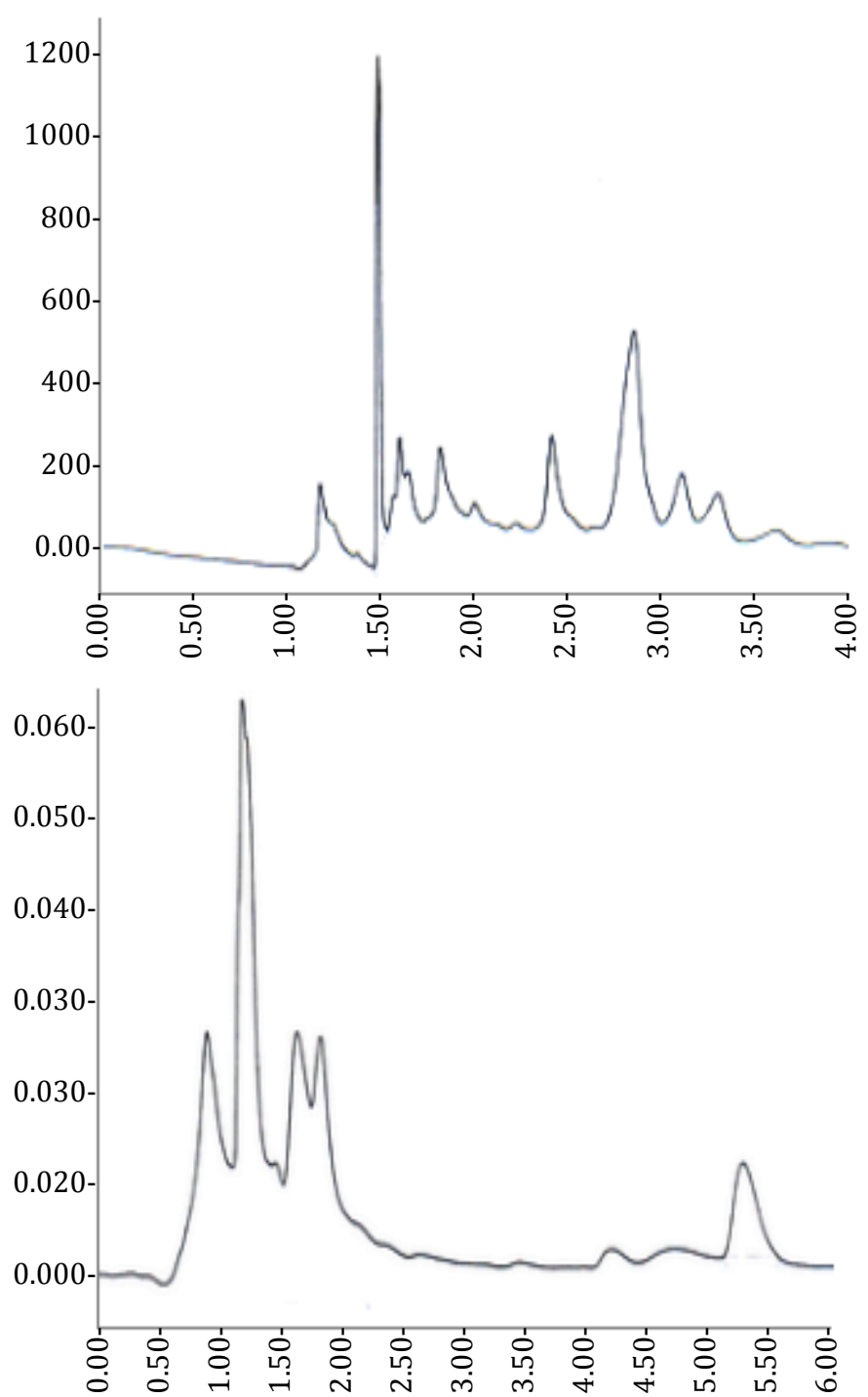

Figure 1. UPLC chromatogram of $\mathrm{FUMB}_{1}, 843.3 \mu \mathrm{g} / \mathrm{g}(\mathrm{A})$, MON, $4.9 \mu \mathrm{g} / \mathrm{g}(\mathrm{B})$, and BEA, $2.8 \mu \mathrm{g} / \mathrm{g}$ ) (C) obtained from corn grits inoculated with $F$. verticillioides, (HLN0155), (OLN03440) and (OLN02000) respectively.

These profiles of mycotoxins have not been reported from Fusarium spp. in Gibberella fujikuroi species complex isolated form stalk and ear rot diseases in Indonesia, Malaysia, and Thailand. Therefore, concerted efforts must be made to educate all stake holders, especially corn farmers and those involve in poultry and animal farming, about the presence and health hazards of these mycotoxins.

\section{ACKNOWLWDGEMENTS}

We are thankful to the RU Research Grant 1001/PBIOLOGI/811182 provided by Universiti Sains Malaysia (USM).

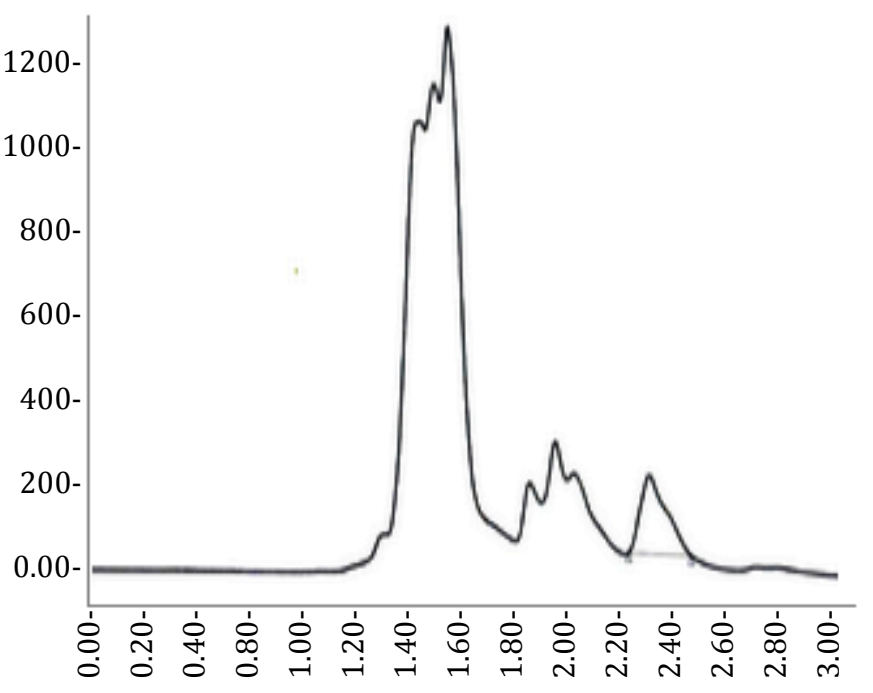

\section{REFERENCES}

Abbas, H.K., C.J. Mirocha and R. Gunther. 1989. Mycotoxins produced by toxic Fusarium isolates obtained from agricultural and nonagricultural areas (Arctic) of Norway. Mycopathologia. 105: 143-151.

Acuna, A., M.C. Lozano, M.C. de-García and G.J. Diaz. 2005. Prevalence of Fusarium species of the Liseola section on selected Colombian animal feedstuffs and their ability to produce fumonisins. Mycopathologia. 160: 63-66.

Bottalico, A., A. Logrieco, A. Ritieni, A. Morretti, G. Randazzo and P. Corda. 1995. Beauvericin and fumonisins $\mathrm{B}_{1}$ in preharvest Fusarium moniliforme maize ear rot in Sardinia. Food Additive and Contaminants. 12: 599-607.

Bottalico, A., A. Logrieco and A. Visconti. 1989.Fusarium species and their mycotoxins in infected cereals in field and in stored grains. In: Chelkowski, J. (ed) Fusarium-Mycotoxins, Taxonomy and Pathogenicity. Topics in Secondary Metabolites. Elsevier, Amsterdam, Netherlands. pp 85-119.

Bullerman, L. B. 1996. Occurrence of Fusarium and fumonisins on food grains and in foods. In: Fumonisins in Food. L.S. Jackson, J.W. Devries, and L.B. Bullerman, eds. Plenum Press: New York. pp 27-38.

Burmeister, H.R., A. Ciegler and R.F. Vesonder. 1979. Moniliformin, a metabolite of Fusarium moniliforme: Purification and Toxicity. Applied and Environmental Microbiol. 37: 11 - 13.

Charmley, L.L., H.L. Trenholm, D.A. Prelusky and A. 
Rosenberg. 1995. Economic losses and decontamination. Natural Toxins. 3: 199-203.

Chelkowski, J., M. Zawadzki, P. Zajkowski, A. Logrieco and A. Bottalico. 1990. Moniliformin production by Fusarium species. Mycotoxins Res. 6: 41-45.

Chulze, S.N., M.L. Ramirez, M. Pascale and A. Visconti. 1998. Fumonisin production by, and mating population of, Fusarium Gibberella fujikuroi species complex isolates from maize in Argentina. Mycological Res. 102: 141-144.

Cole, R.J., J.W. Kirksey, H.G. Cutler, B.L. Doubnik and J.C. Peckham. 1973. Toxin from Fusarium moniliforme: effects on plants and animals. Science. 179: 13241326.

Desjardins, A.E. 2006. Fusarium mycotoxins: chemistry, genetics, and biology. APS St. Paul.

Desjardins, A.E. and T.M. Hohn. 1997. Mycotoxins in plant pathogenesis. Molecular Plant-Microbe Interactions. 10: 147-152.

Desjardins, A.E., H.K. Manandhar, R.D. Plattner, G.G. Manandhar, S.M. Poling and C.M. Maragos. 2000. Fusarium species from Nepalese rice and production of mycotoxins and gibberellic acid by selected species. Applied of Environmental Microbiol. 66: 1020-1025.

Fotso, J., J.F. Leslie and J.S. Smith. 2002. Production of beauvericin, moniliformin, fusaproliferin, and fumonisin $B_{1}, B_{2}$, and $B_{3}$ by ex-type strains of fifteen Fusarium species. Applied and Environmental Microbiology 68: 5195 - 5197.

Gelderblom, W.C.A.J., W.F.O. Jaskiewicz, P.G. Marasas, R.M. Thiel, R.M. Horak, R. Vleggar and N.P.J. Kriek. 1988. Fumonisin mycotoxins with cancerpromoting activity produced by Fusarium moniliforme. Applied of Environmental Microbiol. 54: 1806-1811.

Gutleb, A.C., E. Morrison and A.J. Murk. 2002. Cytotoxicity assays for mycotoxins produced by Fusarium strains: a review. Environmental Toxicology and Pharmacol. 11: 309 - 320.

Krska, R., M. Lemmens, R. Schuchmacher, M. Grasserbauer, M. Pronczuk, H. Wisniewska and J. Chelkowski. 1996. Accumulation of the mycotoxin beauvericin in kernels of corn hybrids inoculated with Fusarium subglutinans. J. of Agricultural and Food Chemistry. 44: 3665-3667.

Leslie, J.F. 1995.Gibberella fujikuroi: Available populations and variable traits. Canadian J. of Botany. 73: 282-291.

Leslie, J.F. and K.K. Klein. 1996. Female fertility and mating type effects on effective population size and evolution in filamentous fungi. Genetics. 144: 557-567.

Leslie, J.F., K.A. Zeller, A. Logrieco, G. Mule, A. Moretti and A. Ritieni. 2004. Species diversity of and toxin production by Gibberella fujikuroi species complex strains isolated from native prairie grasses in Kansas. Applied and Environmental Microbiol. 70: 2254-2262.

Logrieco, A., A. Moretti, G. Castella, M. Kostecki, P. Golinski, A. Ritieni and J. Chelkowski. 1998. Beauvericin production by Fusarium species. Applied and Environmental Microbiol. 64: 30843088.

Logrieco, A., A. Moretti, A. Ritieni, A. Bottalico and P. Corda. 1995. Occurrence and toxigenicity of Fusarium proliferatum from preharvest maize ear rot, and associated mycotoxins, in Italy. Plant Dis. 79: 727-731.

Logrieco, A., G. Mule, A. Moretti and A. Bottalico. 2002. Toxigenic Fusarium species and mycotoxins associated with maize ear rot in Europe. European J. of Plant Pathol. 108: 597-609.

Marasas, W.F.O., T.S. Kellerman, W.C.A. Gelderblom, J.A.W. Coetzer, P.G. Thiel and J.J. Van Der Lugt. 1988. Leukoencephalomalacia in a horse induced by fumonisin $\mathrm{B}_{1}$ isolated from Fusarium moniliforme. Onderstepoort J. Veterinary Res. 55: 197-203.

Marasas, W.F.O., P.E. Nelson and T.A. Toussoun. 1984. Toxigenic Fusarium species. The Pennsylvania State University Press.

Moretti, A., A. Logrieco, A. Bottalico, A. Ritieni, V. Fogliano and G. Randazzo. 1997. Diversity in beauvericin and fusaproliferin production by different populations of Gibberella fujikuroi (Fusarium fujikuroi species complex). Sydowia. 48:44-56.

Moretti, A., G. Mule, A. Susca, M.T. Gonzalez-Jaen and A. Logrieco. 2004. Toxin profile, fertility and AFLP analysis of Fusarium verticillioides from banana fruits. European J. of Plant Pathol. 110: 601-609.

Moss, M.O. 1996. Mycotoxins. Mycological Res. 100: 513523. 
Nelson, P.E. 1992. Taxonomy and biology of Fusarium moniliforme. Mycopathologia. 117: 29-36.

Nelson, P.E., A.E. Desjardins and R.D. Plattner. 1993. Fumonisins, mycotoxins produced by Fusarium species: biology, chemistry and significance. Annual Review of Phytopathol. 31:233-252.

Nelson, P.E., R.D. Plattner, D.D. Shackelford and A.E. Desjardins. 1991. Production of fumonisins by Fusarium moniliforme strains from various substrates and geographic areas. Applied and Environmental Microbiol. 57: 2410 - 2412.

Nur-Ain-Izzati, M.Z., A.A. Razak and B. Salleh. 2009. Bakanae disease of rice in Malaysia and Indonesia: etiology of the causal agent based on morphological, physiological and pathogenicity characteristics. J. of Plant Protection Res. 48: 475485.

Rabie, A.J., W.F.O. Marasas, I.P.G. Thiel, A. Lubben and L.R. Vleggaar. 1982. Moniliformin production and toxicity of different Fusarium species from Southern Africa. Applied and Environmental Microbiol. 43: 517-521.
Shephard, G.S., V. Sewram, T.W. Nieuwoudt, W.F.O. Marasas and A. Ritieni. 1999. Production of the mycotoxins fusaproliferin and beauvericin by South African isolates in the Fusarium Gibberella fujikuroi species complex. J. of Agricultural and Food Chemistry. 47: 5111-5115.

Thiel, P.G., W.F.O. Marasas, E.W. Sydenham, G.S. Shephard, W.C.A. Gelderblom and J.J. Nieuwenhuis. 1991. Survey of fumonisin production by Fusarium species. Appl. Environ. Microbiol. 57:1089-1093.

Thrane, U. and U. Hansen. 1995. Chemical and physiological characterization of taxa in the Fusarium sambucinum complex. Mycopathologia. 129: $183-190$.

Visconti, A. 1996. Fumonisins in maize genotypes grown in various geographic areas. In: Jackson L.S., De Vries, J.W., and Bullermann, L.B. (eds) Advances Experimental Medicine and Biology - Fumonisins in Food. Plenum Press, New York, USA pp 193204.

Weidenbörner, M. 2001. Foods and fumonisins. Eur. Food Res. Technol. 212: 262-273. 